\title{
Emergency department use by pregnant women in Ontario: a retrospective population-based cohort study
}

\author{
Catherine E. Varner MD MSc, Alison L. Park MSc, Darby Little BSc, Joel G. Ray MD MSc
}

\section{Abstract}

Background: Peripregnancy emergency department use may be common, but data specific to health care systems like that in Canada are lacking. As prior research was limited to livebirths, omitting pregnancies ending in miscarriage or induced abortion, the current study quantified and characterized emergency department use among women in Ontario with a recognized pregnancy.

\begin{abstract}
Methods: This retrospective population-based cohort study included all recognized pregnancies among Ontario residents aged 10-55 years with an estimated date of conception between Apr. 1, 2002, and Mar. 31, 2017. We defined peripregnancy emergency department use as any emergency department visit during pregnancy or within 42 days after pregnancy. We used modified Poisson regression with a robust error variance to generate relative risks (RRs) and 95\% confidence intervals (Cls) for the outcome of any peripregnancy emergency department use in association with maternal age, parity, residential income quintile, location of residence, immigrant status, antenatal care provider and number of comorbidities within 120 days before the clinical start of the pregnancy (expressed as total number of Aggregated Diagnosis Groups [ADGs] obtained with the Johns Hopkins Adjusted Clinical Group System). All RRs, except for number of comorbidities, were further adjusted for number of ADGs.
\end{abstract}

Results: Peripregnancy emergency department use occurred in 1075991 (39.4\%) of 2728236 recognized pregnancies, including $35.8 \%$ of livebirths, $47.3 \%$ of stillbirths, $73.7 \%$ of miscarriages and $84.8 \%$ of threatened abortions. A peripregnancy emergency department visit was more likely among women who were less than 25 years of age (adjusted RR 1.16, 95\% $\mathrm{Cl} 1.16-1.17$ ), were nulliparous (adjusted RR 1.13, 95\% Cl 1.13-1.13), resided in the lowest income quintile area (adjusted RR 1.16, 95\% Cl 1.15-1.16) or in a rural area (adjusted RR 1.50, 95\% Cl 1.50-1.51), were Canadian-born (adjusted RR 1.22, 95\% Cl 1.22-1.23), were not seen by an obstetrician (adjusted RR $1.66,95 \% \mathrm{Cl} 1.54-1.80$ ) or had a greater number of ADGs. Emergency department use peaked in the first trimester and in the first week postpartum. Compared to women residing in urban areas, those residing in rural areas had an odds ratio (OR) of $3.44(95 \% \mathrm{Cl} 3.39-3.49)$ for 3 or more emergency department visits. Women with 3-4 (OR 1.99, 95\% Cl 1.972.01), 5-6 (OR 3.55, 95\% Cl 3.49-3.61), or 7 or more (OR 7.59, 95\% Cl 7.39-7.78) prepregnancy comorbidities were more likely to have 3 or more peripregnancy emergency department visits than were those with 2 or fewer comorbidities.

Interpretation: Peripregnancy emergency department use occurred in nearly $40 \%$ of pregnancies, notably in the first trimester and early in the postpartum period. Efforts are needed to streamline rapid access to ambulatory obstetric care during these peak periods, when women are susceptible to miscarriage or a complication after a livebirth.

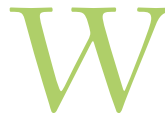

omen use more health care services during pregnancy than at other times. An unforeseen or new-onset health condition - whether in pregnancy or soon after birth - may necessitate an unplanned health care visit(s), including to an emergency department. ${ }^{1}$ A limited number of studies have suggested that emergency department use in pregnancy is often associated with suboptimal antenatal care, psychosocial instability, and worse maternal and infant outcomes. ${ }^{2,3}$ Those studies also documented a higher rate of emergency department use among pregnant women with preexisting comorbidities than among pregnant women without preexisting comorbidities. ${ }^{2-4}$ In the United States, emergency department use during pregnancy has been reported to vary between $21 \%$ and $58 \%$, with a higher frequency of repeat emergency department visits than seen among nonpregnant women..$^{2-5}$ A major limitation of those studies is that the study populations consisted of commercially insured or low-income patients in the US, who likely differ considerably from women who receive care within health care systems such as that in Canada, where there is universal access to physician and hospital care.

\section{Competing interests: None declared.}

This article has been peer reviewed.

Correspondence to: Catherine Varner, catherine.varner@ sinaihealthsystem.ca

CMAJ Open 2020. DOI:10.9778/cmajo.20190154 
Prior research has been limited largely to livebirths, omitting the many pregnancies that end in miscarriage (spontaneous abortion) or induced abortion. In addition, how Canadian women access early pregnancy care differs considerably from how women in other countries with similar health care systems or the US access such care. ${ }^{6,7}$ The aim of the current study was to quantify and characterize emergency department use among women in Ontario who had a recognized pregnancy, including by trimester and within 42 days after pregnancy, and further stratified by pregnancy outcome (livebirth, stillbirth, miscarriage or induced abortion), as well as among women who had a threatened abortion in early pregnancy without a subsequent recognized pregnancy outcome.

\section{Methods}

\section{Setting}

This retrospective population-based cohort study took place in Ontario. All physician and hospital care, including access to obstetric care services, is universally funded for Ontario's residents, and all ambulatory, emergency department and hospital visits by a pregnant woman are documented in provincial health administrative databases.

\section{Study population}

The study population included all recognized pregnancies among Ontario residents aged 10-55 years with an estimated date of conception between Apr. 1, 2002, and Mar. 31, 2017. We defined recognized pregnancy as a livebirth at 20 weeks' or more gestation, stillbirth at 20 weeks' or more gestation, miscarriage (including ectopic pregnancy) before 20 weeks' gestation, induced abortion at any gestational week or threatened abortion (such as vaginal bleeding or unspecified hemorrhage) before 20 weeks' gestation without a subsequent recognized pregnancy outcome. A woman with a threatened abortion whose pregnancy ended in miscarriage in the absence of a health care visit would not necessarily be categorized as having a recognized pregnancy. Although miscarriage is the most probable outcome of those with a threatened abortion, we also analyzed threatened abortion and miscarriage groups separately.

We excluded women and girls without a valid Ontario Health Insurance Plan (OHIP) number, those not resident in Ontario at any point during the index peripregnancy period, and those aged less than 10 years or more than 55 years at the start date of the index pregnancy. We also excluded those with duplicate livebirth or stillbirth delivery records (women who had more than 1 pregnancy during the time period would have each pregnancy counted), implausible maternal death date or implausible gestation length.

\section{Data sources}

This study used health administrative databases for the entire province of Ontario housed at ICES. The databases used were the Canadian Institute for Health Information Discharge Abstract Database, Same Day Surgery Database and National Ambulatory Care Reporting System database, as well as the OHIP claims database, Immigration, Refugees and Citizenship
Canada's Permanent Resident Database and the ICES MOMBABY database, which identifies all hospital liveborn and stillborn maternal-infant pairs (Appendix 1, available at www.cmajopen.ca/content/8/2/E304/suppl/DC1). These data sets, which have been previously validated and used in studies of pregnant women in Ontario, ${ }^{8-11}$ were linked by means of unique encoded identifiers and analyzed at ICES. We defined income quintile and rural residence using Statistics Canada census data. ${ }^{12}$

\section{Outcome measures}

The primary study outcome was peripregnancy use of the emergency department, namely, an emergency department visit during pregnancy or up to 42 days postpartum. The 42-day window after pregnancy is a standard interval used to monitor women's health postpartum. We further delineated emergency department visits by trimester, as well as within the 42-day postpartum period. For the purposes of this study, we defined the 42-day postpartum period as the 42 days following the documented end of the pregnancy, whether that was a livebirth, stillbirth, miscarriage, induced abortion or threatened abortion in the absence of a subsequent documented health care visit.

All emergency department visits were identified in the National Ambulatory Care Reporting System database. An emergency department is a hospital facility that serves unscheduled patients whose conditions may require immediate care and is staffed by physicians 24 hours per day, 7 days per week. An emergency department visit is an encounter in the emergency department between a patient seeking care and a physician or other health care provider (i.e., physician assistant or nurse practitioner working under physician supervision).

\section{Statistical analysis}

We contrasted baseline variables, identified at the estimated clinical start of pregnancy (i.e., 0 weeks' gestation), between women with any emergency department visit in pregnancy or 42 days postpartum, and those without an emergency department visit, using standardized differences.

In the main analysis, we used modified Poisson regression with a robust error variance ${ }^{13}$ to generate relative risks (RRs) and $95 \%$ confidence intervals (CIs) for the outcome of any peripregnancy use of the emergency department in association with maternal age $(<25,25-34$ [referent] or $\geq 35 \mathrm{yr})$, parity (nulliparous v. parous [referent]), residential income quintile (Q1 [lowest] to Q5 [highest; referent]), location of residence (rural v. urban [referent]), immigrant status (foreign-born v. Canadian-born/long-term resident [referent]), antenatal care provider (obstetrician [referent], family physician/nurse practitioner, other provider or none/ unknown) and number of comorbidities within 120 days before the clinical start of the pregnancy (expressed as the total number of Aggregated Diagnosis Groups [ADGs] obtained with the Johns Hopkins Adjusted Clinical Group System: $\leq 2$ [referent], 3-4, 5-6 and 7-32). We determined residential income quintile and location of residence from Statistics Canada census data. We identified immigrant status 
using the Immigration, Refugees and Citizenship Canada Permanent Resident Database, which includes data on country of citizenship for immigrants to Canada since 1985. Women not linked to this database were classified as Canadian-born/long-term resident. All RRs, except for number of comorbidities, were further adjusted for number of ADGs. We used generalized estimating equations to account for the possibility of more than 1 pregnancy per woman during the study period.

We stratified the main analysis by trimester of emergency department use (first $[\leq 13$ gestational wk], second [14-26 gestational $\mathrm{wk}$ ] or third [27-42 gestational $w \mathrm{k}]$ ) or postpartum emergency department use ( $\leq 42 \mathrm{~d}$ postpartum), and by pregnancy outcome (livebirth, stillbirth, miscarriage, induced abortion and threatened abortion). The exact gestational age at birth was known only for livebirth deliveries. Given the greater certainty of the timing of the emergency department visit among livebirths, we also calculated in this group the proportion and $95 \%$ CI for first peripregnancy emergency department visit and for all peripregnancy emergency department visits, by gestational week or postpartum week.

We performed a dose-response analysis to evaluate the odds of a woman's having 1, 2, or 3 or more emergency department visits during the peripregnancy period, in relation to trimester of emergency department use or postpartum emergency department use, and pregnancy outcome. We generated unadjusted odds ratios (ORs) and 95\% CIs using multinomial logistic regression. ${ }^{13}$

We analyzed the data using SAS statistical software, version 9.4 for Unix (SAS Institute) and the Johns Hopkins Adjusted Clinical Group System Version 10. All cell sizes of 5 or fewer were suppressed to prevent reidentification.

\section{Ethics approval}

The use of data in this project was authorized under section 45 of Ontario's Personal Health Information Protection Act, which does not require review by a research ethics board.

\section{Results}

There were 2751829 eligible pregnancies identified, of which $23593(0.8 \%)$ were excluded, owing primarily to an invalid OHIP number, duplicate delivery record, extreme maternal age or non-Ontario residency (Figure 1). Of the 2728236 recognized pregnancies, 1959206 (71.8\%) resulted in a livebirth, $11452(0.4 \%)$ in a stillbirth, $222180(8.1 \%)$ in a miscarriage, $369205(13.5 \%)$ in an induced abortion, and $166193(6.1 \%)$ in a threatened abortion without a recognized pregnancy outcome (Figure 1).

Among the recognized pregnancies, 1075991 women (39.4\%) had a peripregnancy emergency department visit (Table 1). Compared to women who did not visit the emergency department, those who visited the emergency department at least once were more likely to be younger, be Canadian-born or a long-term resident, reside in a rural area and have a greater number of ADGs, and were less likely to have an obstetrician (Table 1). Women who had at least

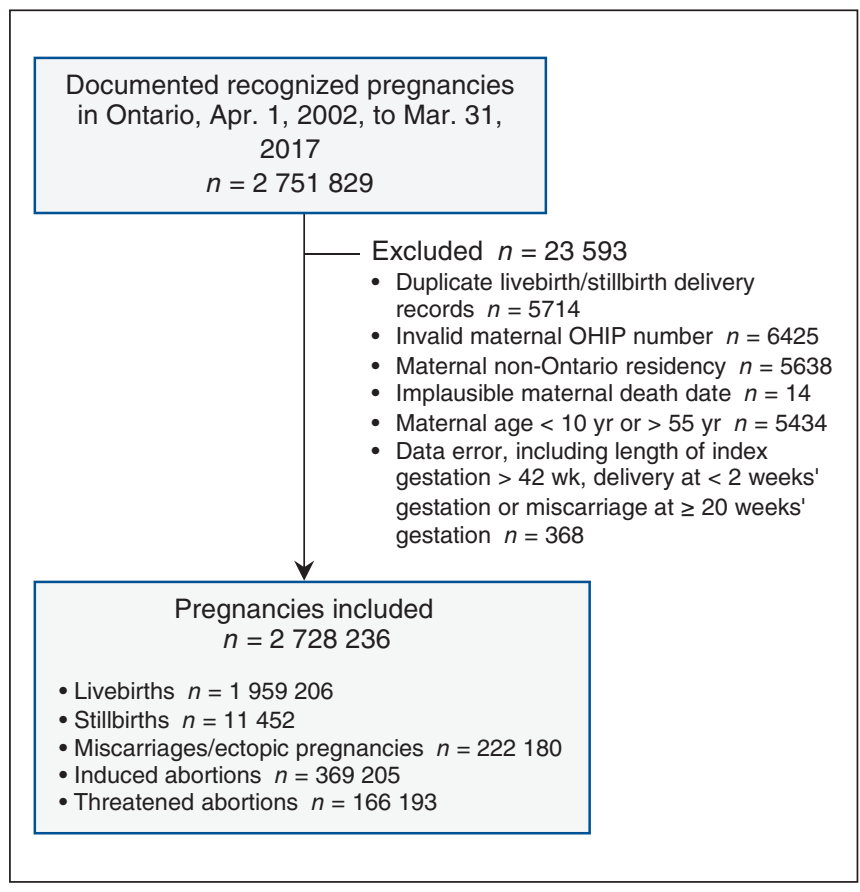

Figure 1: Flow diagram showing cohort creation. Note: OHIP = Ontario Health Insurance Plan.

1 emergency department visit were more likely than those without a visit to have a pregnancy ending in a miscarriage or threatened abortion, and were less likely to have a livebirth or an induced abortion (Table 1). The rate of any peripregnancy use of the emergency department was greater among women who had a threatened abortion $(84.8 \%)$ or miscarriage (73.7\%) than among those who had a stillbirth (47.3\%), livebirth $(35.8 \%)$ or induced abortion $(17.5 \%)$.

Among all recognized pregnancies, a peripregnancy emergency department visit was more likely among women who were less than 25 years of age (adjusted RR 1.16, 95\% CI 1.16-1.17), were nulliparous (adjusted RR 1.13, 95\% CI 1.131.13 ), resided in the lowest income quintile area (adjusted RR $1.16,95 \%$ CI $1.15-1.16$ ) or in a rural area (adjusted RR 1.50, 95\% CI 1.50-1.51), were Canadian-born (adjusted RR 1.22, 95\% CI 1.22-1.23), were not seen by an obstetrician (adjusted RR 1.66, 95\% CI 1.54-1.80) or had a greater number of ADGs (Figure 2). These associations persisted across the trimester of presentation (Appendix 2, Supplemental Figures S1$\mathrm{S} 4$, available at www.cmajopen.ca/content/8/2/E304/suppl/ DC1) and regardless of the pregnancy outcome (Appendix 2, Supplemental Figures S5-S9), with the exception of care provider and trimester of pregnancy.

Among women with a livebirth, emergency department use was most frequent in the first trimester, peaking between 6 and 8 weeks' gestation, and then within the first week postpartum (Figure 3). The same pattern was seen for all emergency department visits, combining first and subsequent emergency department encounters (Appendix 2, Supplemental Figure S10).

A dose-response effect was seen in the number of peripregnancy visits to the emergency department in relation to certain maternal characteristics (Table 2). For example, 
Table 1: Baseline characteristics of pregnant women in Ontario with and without an emergency department visit during pregnancy or up to 42 days postpartum, Apr. 1, 2002, to Mar. 31, 2017

\begin{tabular}{|c|c|c|c|}
\hline \multirow[b]{2}{*}{ Characteristic } & \multicolumn{2}{|c|}{ No. $(\%)$ of women* } & \multirow[b]{2}{*}{ SDiff } \\
\hline & $\begin{array}{c}\text { Any peripregnancy } \\
\text { emergency } \\
\text { department visit } \\
n=1075991\end{array}$ & $\begin{array}{c}\text { No peripregnancy } \\
\text { emergency } \\
\text { department visit } \\
n=1652245\end{array}$ & \\
\hline \multicolumn{4}{|l|}{ At start of pregnancy } \\
\hline Age, yr, mean \pm SD & $28.6 \pm 6.3$ & $29.4 \pm 5.9$ & 0.13 \\
\hline \multicolumn{4}{|l|}{ Age group, yr } \\
\hline $10-19$ & $87466(8.1)$ & $99890(6.0)$ & 0.08 \\
\hline $20-24$ & $201922(18.8)$ & $243707(14.8)$ & 0.10 \\
\hline $25-29$ & $304324(28.3)$ & $457282(27.7)$ & 0.01 \\
\hline $30-34$ & $290357(27.0)$ & $526941(31.9)$ & 0.11 \\
\hline $35-39$ & $147461(13.7)$ & $261792(15.8)$ & 0.06 \\
\hline $40-44$ & 39497 (3.7) & $56970(3.4)$ & 0.01 \\
\hline $45-55$ & $4964(0.5)$ & $5663(0.3)$ & 0.02 \\
\hline \multicolumn{4}{|l|}{ Parity } \\
\hline Median (IQR) & $1.0(0.0-1.0)$ & $1.0(0.0-1.0)$ & 0.06 \\
\hline 0 & $346360(32.2)$ & $591500(35.8)$ & 0.08 \\
\hline 1 & $241345(22.4)$ & $498319(30.2)$ & 0.18 \\
\hline 2 & $99127(9.2)$ & $192334(11.6)$ & 0.08 \\
\hline$\geq 3$ & $52969(4.9)$ & $92190(5.6)$ & 0.03 \\
\hline Missing & $336190(31.2)$ & $277902(16.8)$ & 0.34 \\
\hline \multicolumn{4}{|l|}{ Residential income quintile } \\
\hline 1 (lowest) & $278342(25.9)$ & $373190(22.6)$ & 0.08 \\
\hline 2 & $225928(21.0)$ & $335965(20.3)$ & 0.02 \\
\hline 3 & $213068(19.8)$ & $331653(20.1)$ & 0.01 \\
\hline 4 & $200811(18.7)$ & $331749(20.1)$ & 0.04 \\
\hline 5 (highest) & $152539(14.2)$ & $274042(16.6)$ & 0.07 \\
\hline Missing & $5303(0.5)$ & $5646(0.3)$ & 0.02 \\
\hline Rural residence & $147290(13.7)$ & $113739(6.9)$ & 0.23 \\
\hline Foreign-born & $241984(22.5)$ & $501151(30.3)$ & 0.18 \\
\hline \multicolumn{4}{|l|}{ Antenatal care provider in pregnancy } \\
\hline Obstetrician & $572077(53.2)$ & $1000313(60.5)$ & 0.15 \\
\hline Family physician/nurse practitioner & $180902(16.8)$ & $223570(13.5)$ & 0.09 \\
\hline Other & $260(0.0)$ & $154(0.0)$ & 0.01 \\
\hline None/unknown & $322752(30.0)$ & $428208(25.9)$ & 0.09 \\
\hline \multicolumn{4}{|l|}{$\begin{array}{l}\text { No. of Johns Hopkins ADGs within } 120 \mathrm{~d} \text { before } \\
\text { start of pregnancy }\end{array}$} \\
\hline$\leq 2$ & $753609(70.0)$ & $1319263(79.8)$ & 0.23 \\
\hline $3-4$ & $217573(20.2)$ & $254062(15.4)$ & 0.13 \\
\hline $5-6$ & $76152(7.1)$ & $63630(3.9)$ & 0.14 \\
\hline $7-32$ & $28657(2.7)$ & $15290(0.9)$ & 0.13 \\
\hline \multicolumn{4}{|l|}{ At end of pregnancy } \\
\hline Multiple birth $\dagger$ & $15994(2.3)$ & $20307(1.6)$ & 0.05 \\
\hline No. of weeks of gestation at birth, mean \pm SD $†$ & $38.6 \pm 2.4$ & $38.9 \pm 1.9$ & 0.13 \\
\hline Preterm birth at 20-36 weeks' gestation $†$ & $67526(9.6)$ & $80728(6.4)$ & 0.12 \\
\hline \multicolumn{4}{|l|}{ Outcome of pregnancy } \\
\hline Livebirth at $\geq 20$ weeks' gestation & $701370(65.2)$ & $1257836(76.1)$ & 0.24 \\
\hline Stillbirth at $\geq 20$ weeks' gestation & $5422(0.5)$ & $6030(0.4)$ & 0.02 \\
\hline Miscarriage at $<20$ weeks' gestation & $163747(15.2)$ & $58433(3.5)$ & 0.41 \\
\hline Induced abortion at any gestational week & $64599(6.0)$ & $304606(18.4)$ & 0.39 \\
\hline Threatened abortion at $<20$ weeks' gestation & $140853(13.1)$ & $25340(1.5)$ & 0.46 \\
\hline
\end{tabular}


No. with outcome/no. (\%) at risk

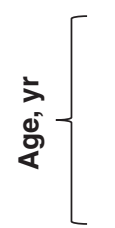

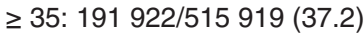

<25: 289 388/633 $234(45.7)$

产

Parous: 393 441/1 177967 (33.4)

Nulliparous: 346 360/938 645 (36.9)

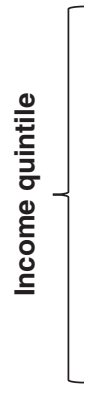

Q5 (highest): 152 539/426 087 (35.8)

Q4: 200 811/532 655 (37.7)

Q3: 213 068/544 931 (39.1)

Q2: 225 928/562 010 (40.2)

Q1 (lowest): 278 342/651 855 (42.7)

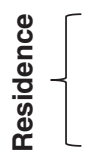

Urban: 928 201/2 468620 (37.6)

Rural: 147 290/261 152 (56.4)

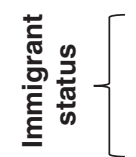

Canadian-born: 834 007/1 985731 (42.0)*

Foreign-born: 241 984/742 282 (32.6)

$\left\{\begin{array}{l}\frac{0}{2} \\ \frac{0}{3} \\ \frac{0}{2} \\ \frac{0}{10} \\ 0\end{array}\right.$

Obstetrician: 572 077/1 571640 (36.4)

None/unknown: 322 752/750 586 (43.0)

Family physician: 180 902/404 702 (44.7)†

Other: 260/414 (62.8)‡

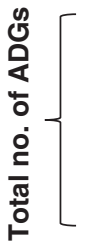

క2: 753 609/2 070354 (36.4)

3-4: $217573 / 471959(46.1)$

5-6: 76 152/139 728 (54.5)

7-32: 28 657/43952 (65.2)

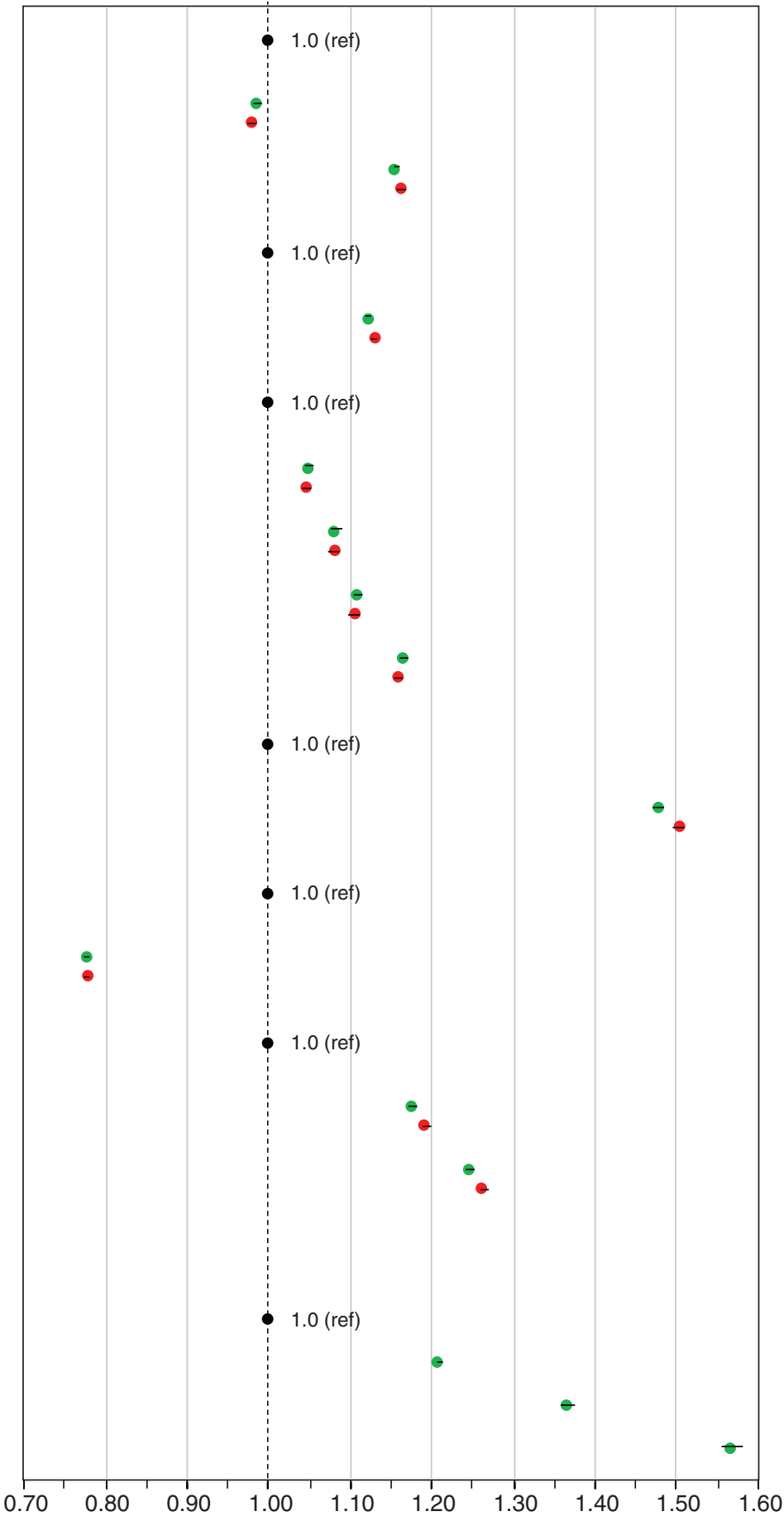

Relative risk

Figure 2: Risk of an emergency department visit during pregnancy or up to 42 days postpartum associated with maternal age, parity, income quintile, residence, immigrant status, care provider and total number of Johns Hopkins Aggregated Diagnosis Groups (ADGs). Relative risks are unadjusted (green dots) and adjusted for the number of ADGs (red dots). Error bars represent 95\% confidence intervals (Cls). ${ }^{*}$ Includes longterm residents. †Includes nurse practitioners. ‡Unadjusted and adjusted relative risks were $1.68(95 \% \mathrm{Cl} 1.55-1.81)$ and $1.66(95 \% \mathrm{Cl}$ $1.54-1.80)$, respectively. Note: ref $=$ referent. 


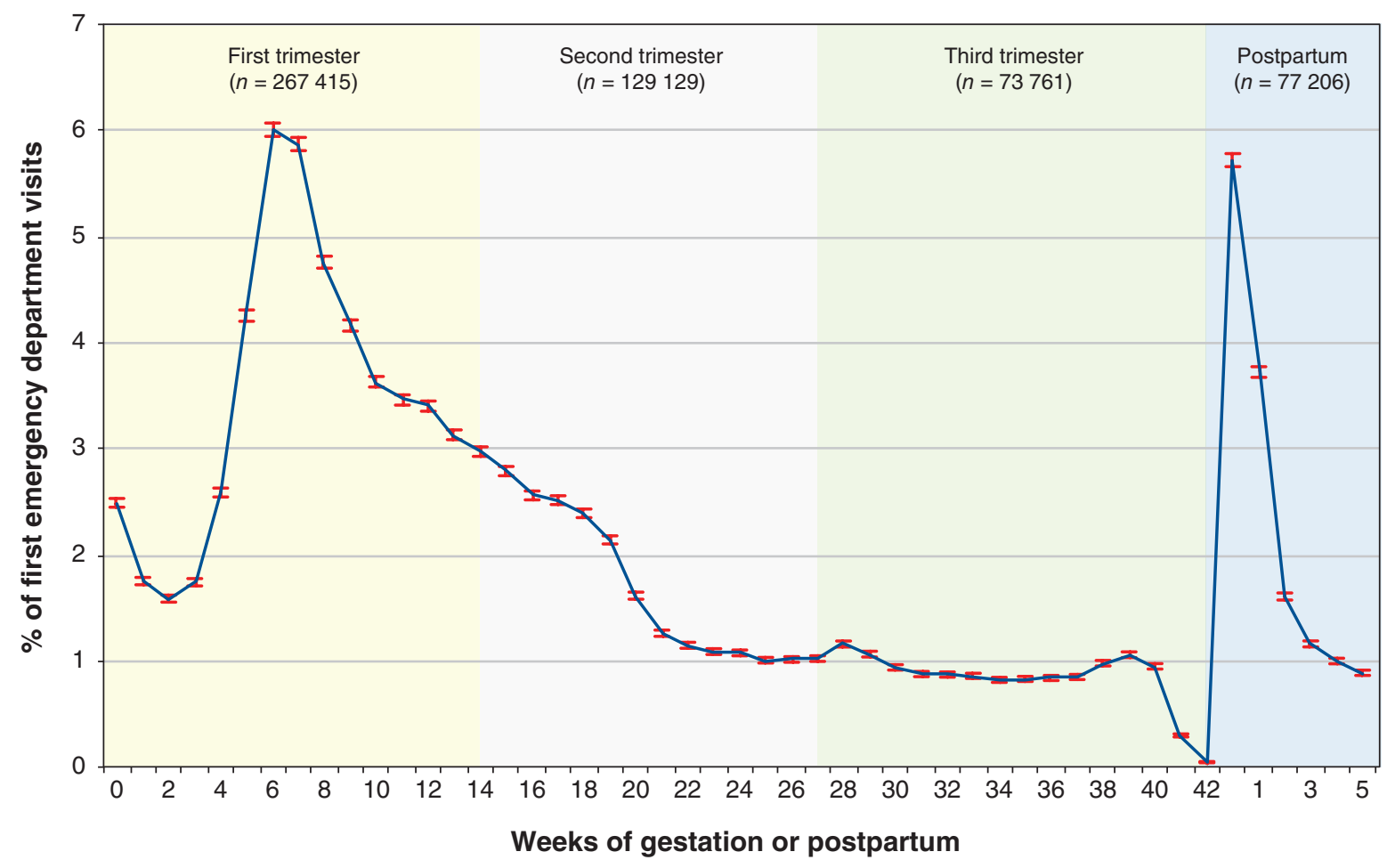

Figure 3: Proportion of first emergency department visits occurring in pregnancy or up to 42 days postpartum among livebirth deliveries. Error bars represent $95 \%$ confidence intervals.

compared to women living in an urban area, rural-dwelling women had an OR of 1.70 (95\% CI 1.69-1.72) for 1 emergency department visit, 2.01 (95\% CI 1.99-2.04) for 2 visits and 3.44 (95\% CI 3.39-3.49) for 3 or more visits. In addition, women with 5-6 ADGs (OR 3.55, 95\% CI 3.49-3.61) or 7 or more ADGs (OR 7.59, 95\% CI 7.39-7.78) were much more likely to have 3 or more emergency department visits than were those with 2 ADGs or fewer (Table 2).

The most frequent diagnoses at the emergency department visit were threatened abortion $(7.7 \%)$, unspecified hemorrhage in early pregnancy $(6.4 \%)$ and spontaneous abortion $(4.5 \%)$. Among all recognized pregnancies in the cohort, only 106989 women (3.9\%) had an injury-related emergency department visit. Among women who had a peripregnancy emergency department visit from 2010/11 to 2017/18, when data on the presenting complaint were available, 287602 $(27.1 \%)$ had a pregnancy-related or postpartum issue (Appendix 3, available at www.cmajopen.ca/content/8/2/E304/suppl/ DC1).

\section{Interpretation}

Nearly $40 \%$ of women in Ontario with a recognized pregnancy between 2002 and 2017 had an emergency department visit around the time of pregnancy. Emergency department use was significantly more likely to occur in the first trimester and in the first week postpartum. Overall, the most common emergency department diagnoses were for conditions arising in the first trimester: threatened abortion, unspecified hemorrhage in early pregnancy and spontaneous abortion.

These findings are similar to US data on peripregnancy use of the emergency department. In a study of $157786 \mathrm{com}-$ mercially insured pregnant patients, the rate of emergency department use was $19.9 \% .{ }^{4}$ It was as high as $57.5 \%$ in a study of low-income pregnant women receiving US Medicaid. ${ }^{5}$ However, Ontario has a single-payer health care system.

Consistent with previous studies, ${ }^{2-5}$ we observed that women with greater comorbidity before pregnancy tended to have multiple emergency department visits during pregnancy and in the first 6 weeks postpartum. We investigated the relation between multimorbidity and recurring emergency department visits and found that women with the greatest prepregnancy comorbidity were 7.6 times more likely to have 3 or more emergency department visits than women with little or no prepregnancy comorbidity. This finding suggests that women with greater prepregnancy comorbidity may benefit from bettercoordinated care in pregnancy, which may lead to fewer acute unscheduled health care visits.

Malik and colleagues ${ }^{2}$ identified other maternal and system-wide factors associated with peripregnancy use of the 
Table 2: Odds of having 1, 2, or 3 or more emergency department visits during pregnancy or up to 42 days postpartum, by maternal characteristics among all recognized pregnancies

\begin{tabular}{|c|c|c|c|c|c|c|}
\hline \multirow[b]{3}{*}{ Characteristic } & \multicolumn{6}{|c|}{ No. of peripregnancy emergency department visits } \\
\hline & \multicolumn{2}{|c|}{1} & \multicolumn{2}{|c|}{2} & \multicolumn{2}{|c|}{$\geq 3$} \\
\hline & $\begin{array}{l}\text { No. }(\%) \text { of } \\
\text { women }\end{array}$ & $\mathrm{OR}^{*}(95 \% \mathrm{Cl})$ & $\begin{array}{l}\text { No. }(\%) \text { of } \\
\text { women }\end{array}$ & $\mathrm{OR}^{\star}(95 \% \mathrm{Cl})$ & $\begin{array}{l}\text { No. }(\%) \text { of } \\
\text { women }\end{array}$ & $\mathrm{OR}^{\star}(95 \% \mathrm{Cl})$ \\
\hline \multicolumn{7}{|l|}{ Age, yr } \\
\hline $25-34$ & $317124(20.1)$ & 1.00 (referent) & $155174(9.8)$ & 1.00 (referent) & $122383(7.8)$ & 1.00 (referent) \\
\hline$\geq 35$ & $106652(20.7)$ & $1.02(1.01-1.03)$ & $51977(10.1)$ & $1.02(1.01-1.03)$ & $33293(6.4)$ & $0.83(0.81-0.84)$ \\
\hline$<25$ & $130923(20.7)$ & $1.18(1.17-1.19)$ & $72826(11.5)$ & $1.34(1.33-1.36)$ & $85639(13.5)$ & $2.00(1.98-2.03)$ \\
\hline \multicolumn{7}{|l|}{ Parity } \\
\hline Parous & $213201(18.1)$ & 1.00 (referent) & $93113(7.9)$ & 1.00 (referent) & $87127(7.4)$ & 1.00 (referent) \\
\hline Nulliparous & $182167(19.4)$ & $1.13(1.12-1.14)$ & $83689(8.9)$ & $1.19(1.18-1.20)$ & $80504(8.6)$ & $1.22(1.21-1.23)$ \\
\hline \multicolumn{7}{|l|}{ Residential income quintile } \\
\hline 5 (highest) & 83998 (19.7) & 1.00 (referent) & $38890(9.1)$ & 1.00 (referent) & $29651(7.0)$ & 1.00 (referent) \\
\hline 4 & $107929(20.3)$ & $1.06(1.05-1.07)$ & $52174(9.8)$ & $1.11(1.09-1.12)$ & $40708(7.6)$ & $1.13(1.12-1.15)$ \\
\hline 3 & $111847(20.5)$ & $1.10(1.09-1.11)$ & $55616(10.2)$ & $1.18(1.16-1.20)$ & $45605(8.4)$ & $1.27(1.25-1.29)$ \\
\hline 2 & $114556(20.4)$ & $1.11(1.10-1.12)$ & 59007 (10.5) & $1.24(1.22-1.26)$ & $52365(9.3)$ & $1.44(1.42-1.46)$ \\
\hline 1 (lowest) & $134037(20.6)$ & $1.17(1.16-1.18)$ & 73029 (11.2) & $1.38(1.36-1.40)$ & $71276(10.9)$ & $1.77(1.74-1.79)$ \\
\hline \multicolumn{7}{|l|}{ Location of residence } \\
\hline Urban & $492363(20.0)$ & 1.00 (referent) & $243572(9.9)$ & 1.00 (referent) & $192266(7.8)$ & 1.00 (referent) \\
\hline Rural & $62075(23.8)$ & $1.70(1.69-1.72)$ & 36279 (13.9) & $2.01(1.99-2.04)$ & $48936(18.7)$ & $3.44(3.39-3.49)$ \\
\hline \multicolumn{7}{|l|}{ Immigrant status } \\
\hline $\begin{array}{l}\text { Canadian-born/ } \\
\text { long-term resident }\end{array}$ & $420188(21.2)$ & 1.00 (referent) & $214463(10.8)$ & 1.00 (referent) & $199356(10.0)$ & 1.00 (referent) \\
\hline Foreign-born & $134511(18.1)$ & $0.74(0.73-0.74)$ & $65514(8.8)$ & $0.70(0.69-0.71)$ & $41959(5.6)$ & $0.48(0.48-0.49)$ \\
\hline \multicolumn{7}{|l|}{ Antenatal care provider } \\
\hline Obstetrician & 303147 (19.3) & 1.00 (referent) & $139075(8.8)$ & 1.00 (referent) & 129855 (8.3) & 1.00 (referent) \\
\hline $\begin{array}{l}\text { Family physician/nurse } \\
\text { practitioner }\end{array}$ & $89278(22.1)$ & $1.32(1.31-1.33)$ & $47797(11.8)$ & $1.54(1.52-1.56)$ & $43827(10.8)$ & $1.51(1.49-1.53)$ \\
\hline Other & $116(28.0)$ & $2.49(1.96-3.15)$ & $78(18.8)$ & $3.64(2.77-4.79)$ & $66(15.9)$ & $3.30(2.46-4.42)$ \\
\hline None/unknown & $162158(21.6)$ & $1.25(1.24-1.26)$ & 93027 (12.4) & $1.56(1.55-1.58)$ & $67567(9.0)$ & $1.22(1.20-1.23)$ \\
\hline \multicolumn{7}{|l|}{$\begin{array}{l}\text { No. of Johns Hopkins } \\
\text { ADGs within } 120 \mathrm{~d} \text { before } \\
\text { start of pregnancy }\end{array}$} \\
\hline$\leq 2$ & 408827 (19.7) & 1.00 (referent) & $197831(9.5)$ & 1.00 (referent) & $146951(7.1)$ & 1.00 (referent) \\
\hline $3-4$ & $104690(22.2)$ & $1.33(1.32-1.34)$ & $56589(12.0)$ & $1.49(1.47-1.50)$ & 56294 (11.9) & $1.99(1.97-2.01)$ \\
\hline $5-6$ & $31828(22.8)$ & $1.61(1.59-1.64)$ & $19173(13.7)$ & $2.01(1.98-2.04)$ & $25151(18.0)$ & $3.55(3.49-3.61)$ \\
\hline $7-32$ & 9354 (21.3) & $1.97(1.92-2.03)$ & $6384(14.5)$ & $2.78(2.70-2.87)$ & $12919(29.4)$ & 7.59 (7.39-7.78) \\
\hline
\end{tabular}

emergency department, including insufficient antenatal care, social instability and worse obstetric outcomes. In the current study, emergency department use spiked at times when a woman is least likely to have access to an obstetric care provider, namely, in the first trimester and in the first week postpartum. This pattern was evident for livebirths, as well as for miscarriages and threatened abortions. Of note, only a very small proportion of emergency department visits appeared to be for conditions such as injury, which an emergency department is best equipped to assess and treat. The evidence suggests that women with pregnancy-related complications in the first trimester often experience long emergency department wait times owing to lack of emergency department resources, such as urgent ultrasonography assessment. ${ }^{14}$ Continuity of 
care is an additional concern, as many women are discharged from the emergency department without a clear care plan or access to a pregnancy care provider, which may expose them to undue risk and complications. ${ }^{7,15}$

The immediate postpartum period is increasingly recognized as a time of greater maternal morbidity and mortality. ${ }^{16}$ The current study and that by Kassebaum and colleagues ${ }^{17}$ suggest that there is a marked increase in emergency department use in the early postpartum period. In a study in the largest inpatient health care delivery system in the US, Clark and colleagues ${ }^{18}$ reported that there were 10751 emergency department visits (4.8\%) among 222084 patients within 42 days of delivery. Fifty percent of the emergency department visits or hospital readmissions occurred within 10 days of discharge. In response, the American College of Obstetricians and Gynecologists proposed a new paradigm of early postpartum care, with ongoing care over several visits within the first 3 weeks postpartum rather than the conventional single visit after 6 weeks. ${ }^{19}$ It is unknown whether this approach can be viably adopted in Canada, especially in rural areas, where obstetric resources are scarce. ${ }^{20}$ Future research is needed to assess whether dedicated pregnancy care in the first trimester and postpartum can improve maternal and fetal outcomes.

\section{Limitations}

Women who experienced a miscarriage but had no pregnancyrelated health care visit would have been missed in the current study. In addition, the outcome was unknown for women diagnosed with a threatened abortion or hemorrhage in early pregnancy with no documented pregnancy outcome thereafter. Certainly, some women with a threatened abortion would be more likely to experience a spontaneous abortion without a subsequent health care visit. Even so, the rate of miscarriage in this cohort is consistent with the rate of recognized miscarriage in large administrative cohorts in the US..$^{21}$

As midwifery billings are not captured in the OHIP database at ICES, women whose pregnancy care, including an outof-hospital birth, was provided entirely by a midwife would have been excluded. Detailed data were also lacking about the acuity of a woman's condition at her emergency department presentation, and the care resources and referrals that ensued in the emergency department or on discharge. Finally, there may have been clustering of women within hospitals where births occur. Even so, most hospitals in Ontario where there are deliveries do not rely on the emergency department for admission to a labour and delivery unit, or for reassessment after delivery. Likewise, many emergency departments are located in hospitals without a birthing facility.

\section{Conclusion}

Within a universal health care system that aims to provide comprehensive prenatal and postnatal care to all women, more than 1 in 3 women used the emergency department during their pregnancy or in the 6 weeks thereafter. Several factors associated with peripregnancy use of the emergency department use, including nulliparity, low income status, rurality, nonobstetrician care provider and higher prepregnancy comorbidity, could inform ongoing efforts to streamline access to ambulatory obstetric care during peak times, such as the first trimester for miscarriage and early postpartum following a livebirth delivery.

\section{References}

1. Magriples U, Kershaw TS, Rising SS, et al. Prenatal health care beyond the obstetrics service: utilization and predictors of unscheduled care. Am 7 Obstet Gynecol 2008;198:75.e1-7.

2. Malik S, Kothari C, MacCallum C, et al. Emergency department use in the perinatal period: an opportunity for early intervention. Ann Emerg Med 2017; 70:835-9.

3. Kilfoyle KA, Vrees R, Raker CA, et al. Nonurgent and urgent emergency department use during pregnancy: an observational study. Am 7 Obstet Gynecol 2017;216:181.e1-7.

4. Cunningham SD, Magriples U, Thomas JL, et al. Association between maternal comorbidities and emergency department use among a national sample of commercially insured pregnant women. Acad Emerg Med 2017;24:940-7.

5. Vladutiu CJ, Stringer EM, Kandasamy V, et al. Emergency care utilization among pregnant Medicaid recipients in North Carolina: an analysis using linked claims and birth records. Matern Child Health f 2019;23:265-76.

6. Rojas-Luengas V, Seaton B, Dainty K, et al. The emergency department experience of patients with early pregnancy complications: a qualitative study. CFEM 2019;21:798-802.

7. Glicksman R, McLeod SL, Thomas J, et al. Services for emergency department patients experiencing early pregnancy complications: a survey of Ontario hospitals. C7EM 2019;21:653-8.

8. Samiedaluie S, Peterson S, Brant R, et al. Validating abortion procedure coding in Canadian administrative databases. BMC Health Serv Res 2016;16:255.

9. Joseph KS, Fahey J; Canadian Perinatal Surveillance System. Validation of perinatal data in the Discharge Abstract Database of the Canadian Institute for Health Information. Chronic Dis Can 2009;29:96-100.

10. Metcalfe A, Lix LM, Johnson JA, et al. Validation of an obstetric comorbidity index in an external population. BJOG 2015;122:1748-55.

11. Aoyama K, Ray JG, Pinto R, et al. Temporal variations in incidence and outcomes of critical illness among pregnant and postpartum women in Canada: a population-based observational study. 7 Obstet Gynaecol Can 2019; 41:631-40.

12. Jaakkimainen L, Upshur REG, Klein-Geltink JE, et al., editors. Primary care in Ontario: ICES atlas. Toronto: ICES; 2006. Available: www.ices.on.ca/flip -publication/primary-care-2006/index.html (accessed 2019 Apr. 15).

13. Zou G. A modified Poisson regression approach to prospective studies with binary data. Am 7 Epidemiol 2004;159:702-6.

14. Tunde-Byass M, Cheung VYT. The value of the early pregnancy assessment clinic in the management of early pregnancy complications. 7 Obstet Gynaecol Can 2009:31:841-4.

15. O'Rourke D, Wood S. The early pregnancy assessment project: the effect of cooperative care in the emergency department for management of early pregnancy complications. Aust NZ Z Obstet Gynaecol 2009;49:110-4.

16. Ray JG, Park AL, Dzakpasu S, et al. Prevalence of severe maternal morbidity and factors associated with maternal mortality in Ontario, Canada. FAMA Netw Open 2018;1:e184571.

17. Kassebaum NJ, Bertozzi-Villa A, Coggeshall M, et al. Global, regional, and national levels and causes of maternal mortality during 1990-2013: a systematic analysis for the Global Burden of Disease Study 2013. Lancet 2014;384: 980-1004.

18. Clark SL, Belfort MA, Dildy GA, et al. Emergency department use during the postpartum period: implications for current management of the puerperium. Am 7 Obstet Gynecol 2010;203:38.e1-6.

19. ACOG Committee Opinion no. 736: optimizing postpartum care. Obstet Gynecol 2018;131:e140-50.

20. Grzybowski S, Stoll K, Kornelsen J. Distance matters: a population based study examining access to maternity services for rural women. BMC Health Serv Res 2011;11:147.

21. Rossen LM, Ahrens KA, Branum AM. Trends in risk of pregnancy loss among US women, 1990-2011. Paediatr Perinat Epidemiol 2018;32:19-29.

Affiliations: Schwartz/Reisman Emergency Medicine Institute (Varner, Little) and Department of Family and Community Medicine (Varner), University of Toronto; University of Toronto (Varner, Little), Sinai Health System; ICES (Park, Ray); Keenan Research Centre (Ray), Li Ka Shing Knowledge Institute and Department of Obstetrics and Gynecology (Ray), St. Michael's Hospital, Toronto, Ont.

Contributors: Catherine Varner and Joel Ray conceived of the study. Catherine Varner, Alison Park and Joel Ray contributed to the study 
design and data interpretation. Alison Park analyzed the data. Catherine Varner, Darby Little and Joel Ray drafted the manuscript. All of the authors revised the manuscript critically for important intellectual content, approved the final version to be published and agreed to be accountable for all aspects of the work.

Funding: This study was funded by an Investigator Award from the University of Toronto Department of Family and Community Medicine and by ICES, which is funded by an annual grant from the Ontario Ministry of Health and Long-Term Care.

Data sharing: The data set from this study is held securely in coded form at ICES. Although data-sharing agreements prohibit ICES from making the data set publicly available, access may be granted to those who meet prespecified criteria for confidential access, available at www.ices.on.ca/DAS. The full data set creation plan and underlying analytic code are available from the authors on request, with the understanding that the computer programs may rely on coding templates or macros that are unique to ICES and are therefore inaccessible or may require modification.

Disclaimer: This study was supported by ICES, which is funded by an annual grant from the Ontario Ministry of Health and Long-Term Care (MOHLTC). The opinions, results and conclusions reported in this article are those of the authors and are independent from the funding sources. No endorsement by ICES or the Ontario MOHLTC is intended or should be inferred. Parts of this material are based on data and information compiled and provided by MOHLTC and the Canadian Institute for Health Information. The analyses, conclusions, opinions and statements expressed herein are solely those of the authors and do not reflect those of the funding or data sources; no endorsement is intended or should be inferred.

Supplemental information: For reviewer comments and the original submission of this manuscript, please see www.cmajopen.ca/content/8/2/ E304/suppl/DC1. 